\title{
Eddy covariance methane flux measurements over a grazed pasture: effect of cows as moving point sources
}

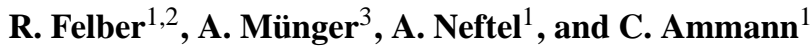 \\ ${ }^{1}$ Agroscope Research Station, Climate and Air Pollution, Zurich, Switzerland \\ ${ }^{2}$ ETH Zurich, Institute of Agricultural Sciences, Zurich, Switzerland \\ ${ }^{3}$ Agroscope Research Station, Milk and Meat Production, Posieux, Switzerland \\ Correspondence to: R. Felber (raphael.felber@agroscope.admin.ch)
}

Received: 21 January 2015 - Published in Biogeosciences Discuss.: 24 February 2015

Revised: 26 May 2015 - Accepted: 08 June 2015 - Published: 29 June 2015

\begin{abstract}
Methane $\left(\mathrm{CH}_{4}\right)$ from ruminants contributes onethird of global agricultural greenhouse gas emissions. Eddy covariance (EC) technique has been extensively used at various flux sites to investigate carbon dioxide exchange of ecosystems. Since the development of fast $\mathrm{CH}_{4}$ analyzers, the instrumentation at many flux sites has been amended for these gases. However, the application of EC over pastures is challenging due to the spatially and temporally uneven distribution of $\mathrm{CH}_{4}$ point sources induced by the grazing animals. We applied EC measurements during one grazing season over a pasture with 20 dairy cows (mean milk yield: $22.7 \mathrm{~kg} \mathrm{~d}^{-1}$ ) managed in a rotational grazing system. Individual cow positions were recorded by GPS trackers to attribute fluxes to animal emissions using a footprint model. Methane fluxes with cows in the footprint were up to 2 orders of magnitude higher than ecosystem fluxes without cows. Mean cow emissions of $423 \pm 24 \mathrm{~g} \mathrm{CH}_{4}$ head ${ }^{-1} \mathrm{~d}^{-1}$ (best estimate from this study) correspond well to animal respiration chamber measurements reported in the literature. However, a systematic effect of the distance between source and EC tower on cow emissions was found, which is attributed to the analytical footprint model used. We show that the EC method allows one to determine $\mathrm{CH}_{4}$ emissions of cows on a pasture if the data evaluation is adjusted for this purpose and if some cow distribution information is available.
\end{abstract}

\section{Introduction}

Methane $\left(\mathrm{CH}_{4}\right)$ is, after carbon dioxide $\left(\mathrm{CO}_{2}\right)$, the second most important human-induced greenhouse gas (GHG), contributing about $17 \%$ of global anthropogenic radiative forcing (Myhre et al., 2013). Agriculture is estimated to contribute about $50 \%$ of total anthropogenic emissions of $\mathrm{CH}_{4}$, while enteric fermentation of livestock alone accounts for about one-third (Smith et al., 2007). For Switzerland these numbers are even higher, with $85 \%$ total agricultural contribution and $67 \%$ from enteric fermentation alone, although still afflicted with considerable uncertainty (Hiller et al., 2014). Measurements of these emissions are therefore important for national GHG inventories and for assessing their effect on the global scale.

Direct measurements of enteric $\mathrm{CH}_{4}$ emissions are commonly made on individual animals using open-circuit respiration chambers (Münger and Kreuzer, 2006, 2008) or the $\mathrm{SF}_{6}$ tracer technique (Lassey, 2007; Pinares-Patiño et al., 2007). Both methods are labor intensive and thus are usually applied only for rather short time intervals (several days). Although the respiration chamber method requires costly infrastructure and investigates animals in spatially constraint conditions, it presently is the reference technique for estimating differences in $\mathrm{CH}_{4}$ emissions related to animal breed and diet.

Recently, micrometeorological measurement techniques have also been tested to estimate ruminant $\mathrm{CH}_{4}$ emissions on the plot scale and compare animal-scale emissions to fieldscale emissions. These approaches are based on average concentration measurements: backward Lagrangian stochastic 
dispersion, mass balance for entire paddocks, and gradient methods (Harper et al., 1999; Laubach et al., 2008; Leuning et al., 1999; McGinn et al., 2011). They have in common that they integrate over a group of animals and are usually applied over specifically designed relatively small fenced plots.

Among the micrometeorological methods, the eddy covariance (EC) approach is considered as the most direct for measuring the trace gas exchange of ecosystems (Dabberdt et al., 1993), and it is used as standard method for $\mathrm{CO}_{2}$ flux monitoring in regional and global networks (e.g., Aubinet et al., 2000; Baldocchi, 2003). Advances in the commercial availability of tunable diode laser spectrometers (Peltola et al., 2013) that measure $\mathrm{CH}_{4}$ (and $\mathrm{N}_{2} \mathrm{O}$ ) concentrations at sampling rates of 10 to $20 \mathrm{~Hz}$ have steadily increased the number of ecosystem monitoring sites measuring also the exchange of these GHG. However, the number of studies made over grazed pastures is still low although such measurements are important to assess the full agricultural GHG budget. Baldocchi et al. (2012) showed the challenge of measuring $\mathrm{CH}_{4}$ fluxes affected by cattle and stressed the importance of position information of these point sources. Dengel et al. (2011) used EC measurements of $\mathrm{CH}_{4}$ fluxes over a pasture with sheep. But the interpretation of the fluxes needed to be based on rough assumptions because the distribution of animals on the (large) pasture was not known.

An ideal requirement for micrometeorological measurements is a spatially homogeneous source area around the measurement tower (Munger et al., 2012), which is often hard to achieve in reality. Although EC fluxes are supposed to represent an average over a certain upwind "footprint" area (Kormann and Meixner, 2001), the effect of stronger inhomogeneity in the flux footprint (FP), like ruminating animals contributing to the $\mathrm{CH}_{4}$ flux, have not been studied in detail. These animals are not always on the pasture (e.g., away for milking) and move around while grazing.They are in varying numbers up- or downwind of the measurement tower and represent non-uniformly distributed point sources. In addition, cows are relatively large obstacles and may distort the wind and turbulence field making the applicability of EC measurement disputable.

The main goal of the present study was to test the applicability of EC measurement for in situ $\mathrm{CH}_{4}$ emission measurements over a pasture with a dairy cow herd under realistic grazing conditions. GPS position data of the individual cows were recorded to know the distribution of the animals and to distinguish contributions of direct animal $\mathrm{CH}_{4}$ release (enteric fermentation) and of $\mathrm{CH}_{4}$ exchange at the soil surface to measured fluxes. Cow attributed fluxes were converted to animal-related emissions using a flux FP model in order to test the EC method in comparison to literature data. Additionally, the following questions were addressed in the study:

- Are animal emissions derived from EC fluxes consistent and independent of the distance of the source?
- How detailed must the cow position information be for the calculation of animal emissions? Does the information about the occupied paddock area reveal results comparable to detailed cow GPS positions?

- Do cows influence the aerodynamic roughness length used by footprint models?

\section{Material and methods}

\subsection{Study site and grazing management}

The experiment was conducted on a pasture at the Agroscope research farm near Posieux on the western Swiss Plateau $\left(46^{\circ} 46^{\prime} 04^{\prime \prime} \mathrm{N}, 7^{\circ} 06^{\prime} 28^{\prime \prime} \mathrm{E}\right)$. The pasture vegetation consists of a grass-clover mixture (mainly Lolium perenne and Trifolium repens) and the soil is classified as stagnic Anthrosol with a loam texture. The vegetation growth was retarded at the beginning of the grazing season due to the colder spring and the wetter conditions during April and May compared to long-term averages. The dry summer (June and July) also led to a shortage of fodder in the study field. Therefore additional neighboring pasture areas were needed to feed the animals.

The staff and facilities at the research farm provided the herd management and automated individual measurements of milk yield and body weight at each milking. Milk was sampled individually 1 day per week and analyzed for its main components. Monthly energy-corrected milk (ECM) yield of the cows was calculated from daily milk yield and the contents of fat, protein, and lactose (Arrigo et al., 1999). Monthly ECM yield decreased over the first 3 months but overall it was fairly constant in time with a mean value of $22.7 \mathrm{~kg}$ and a standard deviation (SD) of $5.5 \mathrm{~kg}$. The average live weight of $640 \mathrm{~kg}(\mathrm{SD} 70 \mathrm{~kg})$ slightly increased by around $6 \%$ over the grazing season.

The field (3.6ha) was divided into six equal paddocks (PAD1 to PAD6) of 0.6 ha each (Fig. 1). The arrangement of the paddocks was chosen to create cases with the herd confined at differing distances to the EC tower. Two main distance classes are used in the following: near cows denotes cases with animals in PAD2 or PAD5, far cows denotes cases with animals in one of the other four paddocks. The present study covers one full grazing season 9 April4 November 2013. Twenty dairy cows were managed in a rotational grazing system during day and night. Depending on initial herbage height the cows typically grazed for 1 to 2 days on a paddock. The herd consisted of Holstein and Red Holstein $\times$ Simmental crossbred dairy cows and was managed with the objective to keep the productivity of the herd relatively constant in time. The cows left the pasture twice a day for milking in the barn where they were also provided with concentrate supplement (usually $<10 \%$ of total diet dry matter) according to their milk production level. The cows left the paddock around 04:00 and 15:00 LT each day but the exact times varied slightly depending on workload in the 


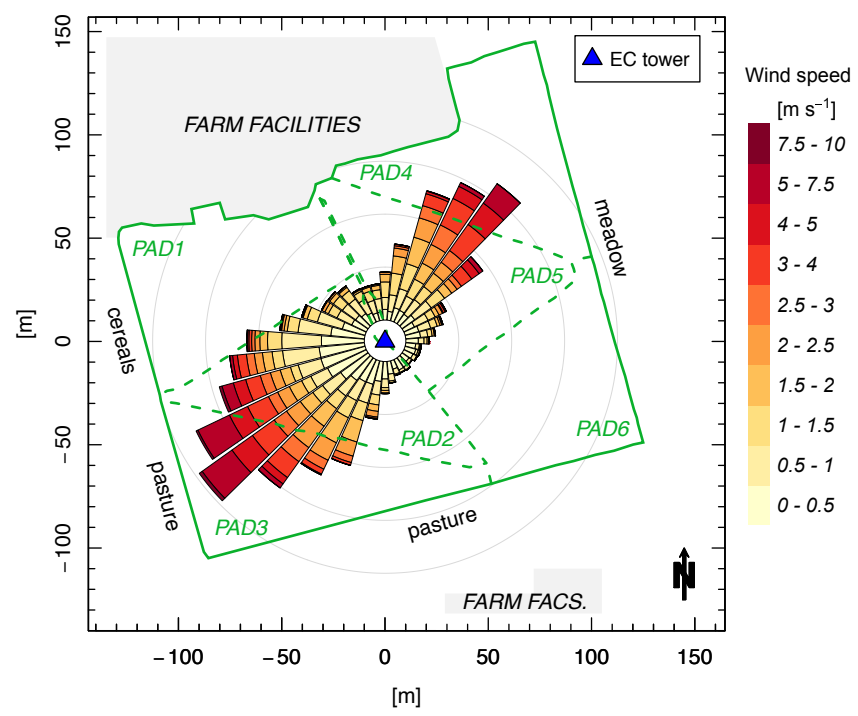

Figure 1. Plan of the measurement site with the pasture (solid green line) and its division into six paddocks, PAD1 to PAD6 (dashed green lines), used for rotational grazing. Around the EC tower in the center, the wind direction distribution for the year 2013 is indicated with a resolution of $10^{\circ}$. The gray circles indicate sector contributions of 2, 4, 6, and $8 \%$ (from inside outwards). Each sector is divided into color shades indicating the occurrence of wind speed classes (see legend).

barn and air temperature. If there was a risk of frost, the cows stayed in the barn overnight (58 nights), and if the daytime air temperature exceeded about $28^{\circ} \mathrm{C}$ before noon, the cows were moved into the barn for shade (19 days). Waterlogged soil condition entirely prohibited grazing on the pasture between 12 and 13 April. In total the cows were grazing on the study field for 198 half-days and for another 157 half-days on nearby pastures not measured by the EC tower.

The management of the neighboring fields is also indicated in Fig. 1. The pastures in the southwest are the additionally used areas due to fodder shortage of the experimental site (see above) and were only used with cows participating in the experiment. The feeding behavior of each cow was monitored by RumiWatch (Itin + Hoch GmbH, Switzerland) halters with a noseband sensor. From the pressure signal time series induced by the jaw movement of the cow (Zehner et al., 2012) the relative duration of three activity classes (eating, ruminating, and idling) was determined using the converter software V0.7.3.2.

\subsection{Eddy covariance measurements}

\subsubsection{Instruments and setup}

The EC measurement tower was placed in the middle of the pasture and was enclosed by a two-wire electric fence to avoid animal interference with the instruments (Fig. 1). The 3-D wind vector components $u, v$ (horizontal), and $w$ (vertical), as well as temperature were measured by an ultrasonic anemometer (Solent HS-50, Gill Instruments Ltd., UK) mounted on a horizontal arm on the tower, $2 \mathrm{~m}$ above ground level. Methane, $\mathrm{CO}_{2}$, and water vapor concentrations were measured with the cavity-enhanced laser absorption technique (Baer et al., 2002) using a fast greenhouse gas analyzer (FGGA; Los Gatos Research Inc., USA). The FGGA was placed in a temperature-conditioned trailer at $20 \mathrm{~m}$ distance (NNE) from the EC tower and was operated in highflow mode at $10 \mathrm{~Hz}$. A vacuum pump (XDS35i Scroll Pump, Edwards Ltd., UK) pulled the sample air through a $30 \mathrm{~m}$ long PVC tube ( $8 \mathrm{~mm}$ ID) and through the analyzer at a flow rate of about 45 SLPM. The inlet of the tube was placed slightly below the center of the sonic anemometer head at a horizontal distance of $20 \mathrm{~cm}$. Two particle filters with liquid water traps (AF30 and AFM30, SMC Corp., JP) were included in the sample line. The $5 \mu \mathrm{m}$ air filter (AF30), installed $1 \mathrm{~m}$ away from the inlet, avoided contamination of the tube walls. The micro air filter (AFM30; $0.3 \mu \mathrm{m}$ ) was installed at the analyzer inlet.

The noise level of the FGGA for fast $\mathrm{CH}_{4}$ measurements depended on the cleanness of the cavity mirrors. It was determined as the (weekly) minimum of the half-hourly standard deviation of the $10 \mathrm{~Hz}$ signal. At the beginning, the noise level was at $15 \mathrm{ppb}$ but gradually increased to $38 \mathrm{ppb}$ over time due to progressive contamination. In July 2013 the noise abruptly increased without any explanation, but cleaning had to be postponed until mid-August. During this period the noise level was 230 to $400 \mathrm{ppb}$. After cleaning, the noise was even lower (around $7 \mathrm{ppb}$ ) than at the beginning.

The gas analyzer was calibrated at intervals of approximately 2 months with two certified standard gas mixtures $\left(1.5 \mathrm{ppm} \mathrm{CH}_{4} / 350 \mathrm{ppm} \mathrm{CO}_{2}\right.$ and $2 \mathrm{ppm} \mathrm{CH}_{4} / 500 \mathrm{ppm}$ $\mathrm{CO}_{2}$; Messer Schweiz AG, Switzerland). The standard gas was supplied with an excess flow via a T-fitting to the device which was set at low measurement mode at $1 \mathrm{~Hz}$ using the internal pump. The calibration showed that the instrument sensitivity did not vary significantly over time, except for the period when the measurement cell was very strongly contaminated.

The data streams of the sonic anemometer and the dry air mixing ratios from the FGGA instrument were synchronized in real-time by a customized LabView (LabView 2009, National Instruments, USA) program and stored as raw data in daily files for offline analysis.

Standard weather parameters were measured by a customized automated weather station (Campbell Scientific Ltd., UK).

\subsubsection{Flux calculation}

Fluxes were calculated for $30 \mathrm{~min}$ intervals by a customized program in R software (R Core Team, 2014). First, each raw $10 \mathrm{~Hz}$ time series was filtered for values outside the physically plausible range ("hard flags") and the sonic data (wind 


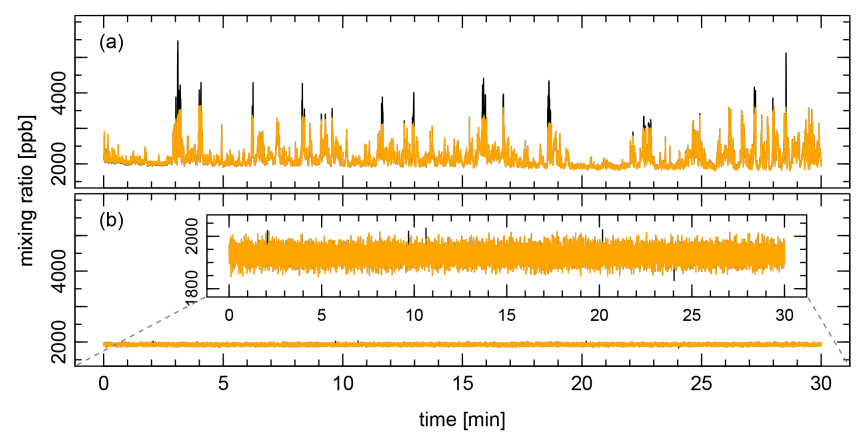

Figure 2. $10 \mathrm{~Hz}$ time series of $\mathrm{CH}_{4}$ mixing ratio for two exemplary 30 min intervals on 15 June 2013 between 12:30 and 14:30 local time (a) with and (b) without cows in the FP. In black, untreated data; in orange, data after de-spiking. The two cases correspond to the cross-covariance functions in Fig. $3 a$ and $b$.

and temperature) were subject to a de-spiking (“soft flags") routine according to Schmid et al. (2000); replacing values that exceed 3.5 times the standard deviation within a running time window of $50 \mathrm{~s}$. Filtered values were counted and replaced by a running mean over 500 data points. No de-spiking was applied for the $\mathrm{CH}_{4}$ mixing ratio because a potentially large effect on resulting fluxes was found. For cases with cows in the FP, the $\mathrm{CH}_{4}$ concentration showed many large peaks as illustrated in Fig. 2a, whereas for conditions without cows the variability range was much lower (Fig. 2b). When the de-spiking routine is applied to the time series, this has a strong effect in the case with cows in the FP (Fig. 2a). In this 30 min interval, 454 data points are replaced and the remaining concentration data are limited to $3500 \mathrm{ppb}$. The corresponding flux is reduced from 1322 to $981 \mathrm{nmol} \mathrm{m}^{-2} \mathrm{~s}^{-1}(-26 \%)$. The second time series not influenced by cows shows no distinct spikes and only five data points are removed by the de-spiking routine without significant effect on the resulting flux. Prior to the covariance calculation, the wind components were rotated with the double rotation method (Kaimal and Finnigan, 1994) to align the wind coordinate system into the mean wind direction, and the scalar variables were linearly detrended.

The EC flux is defined as the covariance between the vertical wind speed and the trace gas mixing ratio (Foken et al., 2012b). Due to the tube sampling of the FGGA instrument there is a lag time between the recording of the two quantities. Therefore, the $\mathrm{CH}_{4}$ flux was determined in a three-stage procedure: (i) for all $30 \mathrm{~min}$ intervals, the maximum absolute value (positive or negative) of the cross-covariance function and its lag position ("dynamic lag") was searched for within a lag time window of $\pm 50 \mathrm{~s}$; (ii) the "fixed lag" was determined as the mode (most frequent value) of observed dynamic lags over several days allowing for longer-term temporal changes due to the FGGA operational conditions; (iii) for the final data set, the flux at the fixed lag was taken if the deviation between the dynamic and the fixed lag was larger than $0.36 \mathrm{~s}$

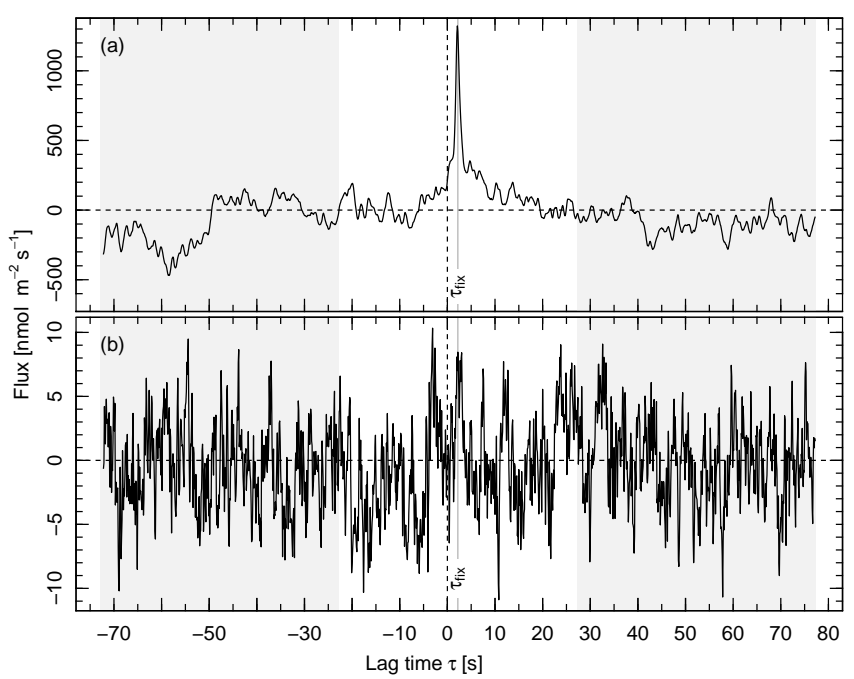

Figure 3. Cross-covariance function of $\mathrm{CH}_{4}$ fluxes for two $30 \mathrm{~min}$ intervals of 15 June 2013 (a) with and (b) without cows in the footprint. The panels correspond to the intervals in Fig. 2. $\tau_{\text {fix }}$ indicates the expected fixed lag time for the EC system. The gray areas on both sides indicate the ranges used for estimating the flux uncertainty and detection limit.

else the flux at the dynamic lag was taken. The fixed lag for the $\mathrm{CH}_{4}$ flux in this study was around $2 \mathrm{~s}$.

For large emission fluxes with cows in the FP, a pronounced and well-defined peak in the cross-covariance function could be found close to the expected lag time (Fig. 3a). For small fluxes, the peak may be hidden in the randomlike noise of the cross-covariance function and the maximum value may be found at an implausible dynamic lag position (Fig. 3b). In this case, the flux at the fixed lag is more representative on statistical average because it is not biased by the maximum search.

The air transportation through the long inlet tube $(30 \mathrm{~m})$ and the filters led to high-frequency loss in the signal (Foken et al., 2012a). To determine the damping factor, sufficient flux intervals with good conditions are needed, i.e., cases with a large significant flux and very stationary conditions resulting in a well-defined cospectrum and ogive with a low noise level. These requirements were generally fulfilled better for $\mathrm{CO}_{2}$ than for $\mathrm{CH}_{4}$ fluxes. Because both quantities were measured by the same device, we assumed that $\mathrm{CH}_{4}$ fluxes had the same high-frequency loss as determined for the more significant $\mathrm{CO}_{2}$ fluxes. High-frequency loss was calculated by the "ogive" method as described in Ammann et al. (2006). In short, the damping factor was calculated by fitting the normalized cumulative co-spectrum of the trace gas flux to the normalized sensible heat flux co-spectrum at the cut-off frequency of $0.065 \mathrm{~Hz}$. The minor high-frequency damping of the sensible heat flux itself was calculated according to Moore (1986). A total damping of 10 to $30 \%$, de- 
pending mainly on wind speed, was found for the presented setup, and the fluxes were corrected for this effect.

The mixing ratios measured by the FGGA were internally corrected for the amount of water vapor (at $10 \mathrm{~Hz}$ ) and stored as "dry air" values. Since temperature fluctuations are supposed to be fully damped by the turbulent flow (Reynolds number of 10000) in the long inlet line, no further correction for correlated water vapor and temperature fluctuations (Webb, Pearman, and Leuning (WPL) density correction, Webb et al., 1980) was necessary.

\subsubsection{Detection limit and flux quality selection}

The flux detection limit was determined by analyzing the cross-covariance function of fluxes dominated by general noise, i.e., fixed lag cases without significant covariance peaks. Additionally, the selection was limited to smaller fluxes (in the range around zero for which more fixed lag than dynamic lag cases were found, here $\pm 26 \mathrm{nmol} \mathrm{m}^{-2} \mathrm{~s}^{-1}$ ) in order to exclude cases with unusually high non-stationarity effects. The uncertainty of the noise dominated fluxes was determined from the variability (standard deviation) of two $50 \mathrm{~s}$ windows on the left and the right side of the covariance function (Fig. 3) similar to Spirig et al. (2005). The detection limit was determined as 3 times the average of these standard deviations.

All measured EC fluxes were selected using basic quality criteria. The applied limits were chosen based on theoretical principles and statistical distributions of the tested quantities. Only cases which fulfilled the following criteria were used for calculations:

- less than 10 hard flags in wind and concentration time series,

- small vertical vector rotation angle (tilt angle) within $\pm 6^{\circ}$ to exclude cases with non-horizontal wind field,

- wind direction within sectors 25 to $135^{\circ}$ and 195 to $265^{\circ}$ to exclude cases that were affected by the farm facilities to the north and to the south of the study field (by non-negligible flux contribution, non-stationary advection, distortion of wind field, and turbulence structure),

- fluxes above the detection limit need a significant covariance peak (dynamic lag determination).

Moving sources in the FP lead to strong flux variations which are normally identified by the stationarity criterion (Foken et al., 2012a). We did not apply a stationarity test because it would have potentially removed cases with high cow contributions. We also did not apply a $u_{*}$ threshold filter that is often used for $\mathrm{CO}_{2}$ flux measurements (Aubinet et al., 2012) because it would have been largely redundant with the other applied quality selection criteria (with a negligible effect of $<2 \%$ on mean emissions). Table 1 shows the reduction in number of fluxes due to the quality selection criteria.

\subsection{GPS method for deriving animal $\mathrm{CH}_{4}$ emission}

To assess the reliability of EC flux measurements of $\mathrm{CH}_{4}$ emissions by cows on the pasture, the measured fluxes $\left(F_{\mathrm{EC}}\right)$ had to be converted to average cow emissions $(E)$ per animal and time. This was done using three different information levels about animal position and distribution on the pasture:

1. GPS method: use of time-resolved position for each animal from GPS cow sensors (this section),

2. PAD method: use of detailed paddock stocking time schedule (Sect. 2.4),

3. FIELD method: using only the seasonal average stocking rate on the measurement field without stocking schedule details (Sect. 2.5).

\subsubsection{Animal position tracking}

For animal position tracking, each cow was equipped with a commercial hiking GPS device (BT-Q1000XT, Qstarz Ltd., Taiwan) attached to a nylon web halter at the cows neck to optimize satellite signal reception. The GPS loggers using the WAAS, EGNOS, and MSAS correction (Witte and Wilson, 2005) continuously recorded the position at a rate of $0.2 \mathrm{~Hz}$. Each GPS device was connected to a modified battery pack with three $3.6 \mathrm{~V}$ lithium batteries to extend the battery lifetime up to 10 days. GPS data were collected from the cow sensors weekly during milking time, and at the same occasion also the batteries were exchanged. GPS coordinates were transformed from the World Geodetic System (WGS84) to the metric Swiss national grid (CH1903 LV95) coordination system. GPS data were filtered for cases with low quality depending on satellite constellation (positional dilution of precision PDOP $\leq 5$ ). Each track was visually inspected for malfunction to exclude additional bad data not excluded by the PDOP criterion. Smaller gaps $(<1 \mathrm{~min})$ in the GPS data of individual cow tracks were linearly interpolated. The total coverage of available GPS data was used as a quality indicator for each $30 \mathrm{~min}$ interval. The position data were used to distinguish between 30 min intervals when the cows were on the study field or elsewhere (barn or other pasture), or moving between the barn and the pasture.

The accuracy of the GPS devices was assessed by a fixed point test with six devices placed directly side by side for 5 days. Each device showed an individual variability in time not correlated to other devices and some systematic deviation from the overall mean position (determined from very good data with PDOP $<2$ of all devices). The accuracy of each device was calculated as the $95 \%$ quantile of deviations. It ranged from 1.9 to $4.3 \mathrm{~m}$ for the six devices. We assessed this accuracy as sufficient for the present experiment because it is much smaller than the typical flux FP extension and also smaller than the typical cow movement range within a $30 \mathrm{~min}$ interval. Although some sensor malfunctions and data losses 
Table 1. Number of available $30 \mathrm{~min} \mathrm{CH}_{4}$ fluxes in this study after the application of selection criteria for the three calculation methods (FIELD, GPS, and PAD method). Bold numbers were used for final calculations.

\begin{tabular}{|c|c|c|c|c|c|c|}
\hline & \multirow[t]{2}{*}{ all/FIELD } & \multicolumn{3}{|c|}{ GPS } & \multicolumn{2}{|c|}{ PAD } \\
\hline & & soil & $\begin{array}{l}\text { near } \\
\text { cows }\end{array}$ & $\begin{array}{r}f a r \\
\text { cows }\end{array}$ & $\begin{array}{l}\text { near } \\
\text { cows }\end{array}$ & $\begin{array}{r}\text { far } \\
\text { cows }\end{array}$ \\
\hline Grazing season $^{1}$ & 10080 & & & & & \\
\hline Quality operation ${ }^{2}$ & 9856 & & & & & \\
\hline Quality turbulence 3 & 7093 & & & & & \\
\hline Wind direction ${ }^{4}$ & 4645 & & & & & \\
\hline Flux error/LoD ${ }^{5}$ & 3630 & & & & & \\
\hline Soil/cow attrib. $^{6}$ & & 2076 & 205 & 64 & 216 & 74 \\
\hline Outliers removed $^{7}$ & & 1917 & 194 & 63 & 198 & 74 \\
\hline $\begin{array}{l}1 \text { Total number of } 30 \text { min int } \\
2 \text { Available data with proper } \\
3 \text { Acceptable quality of turb } \\
{ }^{3} \text { Accepted (undisturbed) wi } \\
{ }^{5} \text { No fluxes at fixed lag if flu } \\
6 \text { Split fluxes based on GPS } \\
\text { intervals ( } 730 \text { ) when cows } \mathrm{w} \\
\text { intermediate mean cow FP } \\
7 \text { Outliers for cow cases dete }\end{array}$ & $\begin{array}{l}\text { vals in grazing se } \\
\text { strument operati } \\
\text { ence parameters a } \\
\text { direction: } 25 \text { to } \\
\text { larger than flux d } \\
\text { ta; exclusion of i } \\
\text { e being moved b } \\
\text { ights. } \\
\text { nined based on e }\end{array}$ & $\begin{array}{l}\text { ason }(9 \mathrm{~A} \\
\text { n (hard fl} \\
\text { nd vertica } \\
135^{\circ} \text { and } \\
\text { etection li } \\
\text { tervals w } \\
\text { tween bar } \\
\text { nissions ( }\end{array}$ & $\begin{array}{l}\text { ril-4 Apr } \\
\text { gs }<10) \text {. } \\
\text { tilt angle } \\
95 \text { to } 265 \\
\text { it (LoD). } \\
\text { h low GP } \\
\text { and past } \\
\text { cow). }\end{array}$ & $\begin{array}{l}\text { 2013). } \\
\text { vithin } \pm 6\end{array}$ & $\begin{array}{l}\text { rage; ex } \\
\text { ing of ca }\end{array}$ & $\begin{array}{l}\text { ion of } \\
\text { with }\end{array}$ \\
\hline
\end{tabular}

for individual GPS sensors occurred during the continuous operation, the overall data coverage was satisfactory for sensors attached to animals. Time intervals with less than $70 \%$ of cow GPS positions available, were discarded from the data evaluation. This occurred in only $8 \%$ of the cases.

\subsubsection{Footprint calculations}

An EC flux measurement represents a weighted spatial average over a certain upwind surface area called flux FP. The FP weighting function can be estimated by dispersion models. Kormann and Meixner (2001) published a FP model (KM01) based on an analytical solution of the advection-dispersion equation using power functions to describe the vertical profiles. The basic Eq. (1) describes the weight function $\varphi$ of the relative contribution of each upwind location to the observed flux with the $x$ coordinate for longitudinal and $y$ coordinate for lateral distance.

$\varphi(x, y)=\frac{1}{\sqrt{2 \pi} \cdot \mathrm{D} \cdot x^{\mathrm{E}}} e^{\frac{-y^{2}}{2 \cdot\left(D \cdot x^{E}\right)^{2}}} \cdot \mathrm{C} \cdot x^{-\mathrm{A}} \cdot e^{\frac{-\mathrm{B}}{x}}$

The terms $A$ to $E$ are functions of the necessary micrometeorological input parameters $(z-d$ : aerodynamic height of the flux measurement; $u_{*}$ : friction velocity; $L$ : Monin-Obukhov length; $\sigma_{v}$ : standard deviation of the lateral wind component; wd: wind direction; $\bar{u}$ : mean wind speed) which were measured by the EC system.

The FP weight function also needs the aerodynamic roughness length $\left(z_{0}\right)$ as input parameter. It can be calculated as described in Neftel et al. (2008) from the other input parameters $z-d, u_{*}, L$, and $\bar{u}$ by solving the following wind profile relationship:

$\bar{u}(z-d)=\frac{u_{*}}{k}\left[\ln \left(\frac{z-d}{z_{0}}\right)-\psi_{H}\left(\frac{z-d}{L}\right)\right]$.

However, the determination of $z_{0}$ with this equation is sensitive to the quality of the other parameters and especially problematic in low-wind conditions with relatively high uncertainty in the measured $u_{*}$. Because $z_{0}$ is considered approximately constant for given grass canopy conditions, its average seasonal course for the measurement field was parameterized by fitting a polynomial to individual results of Eq. (2) which fulfilled the following criteria: $\bar{u}>1.5 \mathrm{~m} \mathrm{~s}^{-1}$ (see e.g., Graf et al., 2014), days without snow cover, and mean wind direction in the undisturbed sectors 25 to $135^{\circ}$ and 195 to $265^{\circ}$ (other wind direction showed relatively large variation of $z_{0}$ ).

Because of short-term variability in the vegetation cover and because of the potential impact of cows on $z_{0}$, a range of a factor of 3 on both sides of the fitted parameterization (see Fig. 7) was defined. If the individual $30 \mathrm{~min} z_{0}$ value (derived with Eq. 2) was within this range, it was directly used for the FP calculation. If $z_{0}$ exceeded this range it was restricted to the upper/lower bound of the range.

Assuming that each cow represents a (moving) point source of $\mathrm{CH}_{4}$, the $\mathrm{FP}$ contribution of each $5 \mathrm{~s}$ cow position (Fig. 4a) was calculated according to Eq. (1). The individual values were then averaged for each $30 \mathrm{~min}$ interval to the mean FP weight of a cow $\bar{\varphi}_{\text {cow }}$ and of the entire cow herd $\bar{\varphi}_{\text {herd }}$ :

$\bar{\varphi}_{\text {herd }}=n_{\text {cow }} \cdot \bar{\varphi}_{\text {cow }}=n_{\text {cow }} \cdot\left[\frac{1}{\mathrm{~N}} \sum_{i=1}^{N} \varphi\left(x_{i}, y_{i}\right)\right]$, 
with $n_{\text {cow }}$ denoting the number of cows in the herd, and $N$ the total number of available GPS data points within the $30 \mathrm{~min}$ interval. To account for the uncertainty of the GPS position, each data point was blurred by adding $4 \mathrm{~m}$ in each direction from the original point. $\varphi\left(x_{i}, y_{i}\right)$ was calculated as the mean of the five $\varphi(x, y)$. Values of $\bar{\varphi}_{\text {herd }}$ were accepted only for 30 min intervals where $>70 \%$ of the GPS data was available and the input parameters $L, u_{*}$, and $\sigma_{v}$ were of sufficient quality. According to Eq. (3) it was assumed implicitly that the FP weight of the cows with missing GPS data corresponded to the mean weight of the cows with available position data.

\subsubsection{Calculation of average cow emission}

The measured flux $\left(F_{\mathrm{EC}}\right)$ cannot be entirely attributed to the contribution of direct cow emissions within the FP. It also includes the $\mathrm{CH}_{4}$ exchange flux of the pasture soil (including the excreta patches). This contribution is denoted as "soil flux" $\left(F_{\text {soil }}\right)$ in the following. $F_{\text {soil }}$ had to be quantified by selecting fluxes with no or negligible influence of cows based on the GPS FP evaluation and other selection criteria (Table 1).

The GPS data allows for the calculation of emissions based on actual observed cow distribution and the use of the average herd FP weights (Eq. 3). The average emission per cow $\left(E_{\text {cow }}\right)$ for a 30 min interval is determined as

$E_{\mathrm{cow}}=\frac{\left(F_{\mathrm{EC}}-F_{\text {soil }}\right)}{\bar{\varphi}_{\text {herd }}}$.

In addition to the quality selection criteria for the EC fluxes mentioned in Sect. 2.2.3, the $E_{\text {cow }}$ and the $F_{\text {soil }}$ data sets were subject to an outlier test and removal. Outliers were identified using the box plot function of R (R Core Team, 2014) as values with a distance from the box (inter-quartile rage) of greater than 1.5 times the length of the box. The effect of the outlier removal on the number of available data is indicated in Table 1.

\subsection{PAD method for deriving animal $\mathrm{CH}_{4}$ emission}

To assess the effect of the precision of cow position information on the determination of the average cow emission, an option with less detailed but easier to obtain position information was also applied and compared to the GPS approach. In the PAD method, no individual cow position information is used, but it is assumed that the animal $\mathrm{CH}_{4}$ source is evenly distributed over the occupied paddock area. For this approach, an accurate paddock stocking time schedule is needed.

\subsubsection{Footprint calculation for paddocks}

Neftel et al. (2008) developed a FP tool based on Eq. (1) that calculates the FP weights of quadrangular areas upwind of an EC tower. The source code was adapted and transferred

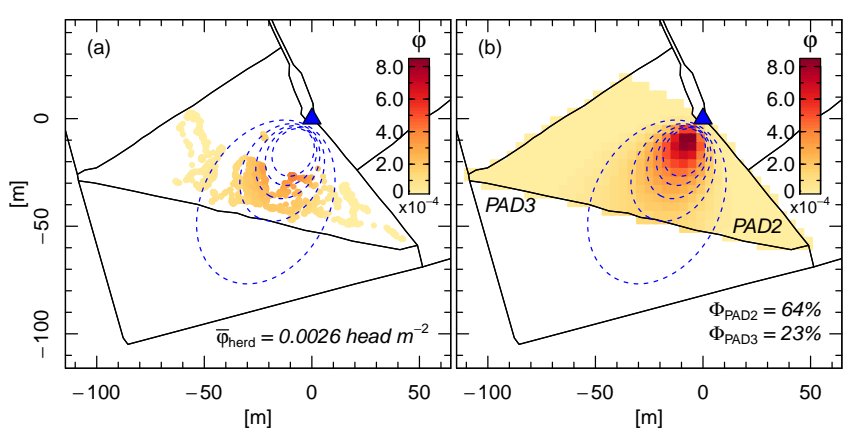

Figure 4. Determination of footprint weights for a cow herd in PAD2 during a $30 \mathrm{~min}$ interval with two different approaches: (a) GPS method (Eq. 3) based on the actual cow positions; (b) PAD method (Eq. 5) calculating the area integrated footprint weight of the entire paddock area (here $\Phi_{\mathrm{PAD} 2}=64 \%$ ) with the resolution of a $4 \times 4 \mathrm{~m}$ grid. The reddish color scale indicates the footprint weight of each location. The blue triangle indicates the position of the EC tower and the blue dashed lines are isolines of the footprint weight function.

to an $\mathrm{R}$ routine in order to allow for more complex polygons instead of quadrangles for the different sub-areas of interest (here paddocks).

Under the assumption that an observed flux originates from a known source and that the source is uniformly distributed over a defined paddock area, the measured fluxes can be corrected with the integrated FP weight (Neftel et al., 2008):

$\Phi_{\mathrm{PAD}}=\iint_{\mathrm{PAD} \text { area }} \varphi(x, y) d x d y$.

In the FP tool, the domain which covers $99 \%$ of the FP is divided into a grid of $200 \times 100$ (along-wind by crosswind) cells, and for each cell the FP weight is calculated. The sum of all cells lying in the area of interest is the FP weight of the area (Eq. 5 and Fig. 4b). The FP model had already been validated in a field experiment with a grid of artificial $\mathrm{CH}_{4}$ sources and two EC flux systems (Tuzson et al., 2010).

\subsubsection{Determination of average cow emission}

With the information on pasture time and occupied paddock number, the average cow emission for a $30 \mathrm{~min}$ interval is calculated as

$E_{\mathrm{cow}}=\frac{\left(F_{\mathrm{EC}}-F_{\mathrm{soil}}\right) \cdot A_{\mathrm{PAD}}}{\Phi_{\mathrm{PAD}}} \cdot \frac{1}{n_{\mathrm{cow}}}$,

with $n_{\text {cow }}$ denoting the number of cows in the occupied paddock, $A_{\mathrm{PAD}}$ the area, and $\Phi_{\mathrm{PAD}}$ the FP fraction of the corresponding paddock. Emissions are calculated only for the 30 min intervals where the cows were on the pasture, the FP weight of the grazed paddock $\Phi_{\mathrm{PAD}}$ exceeds 0.1 , and FP input parameters are of sufficient quality. 


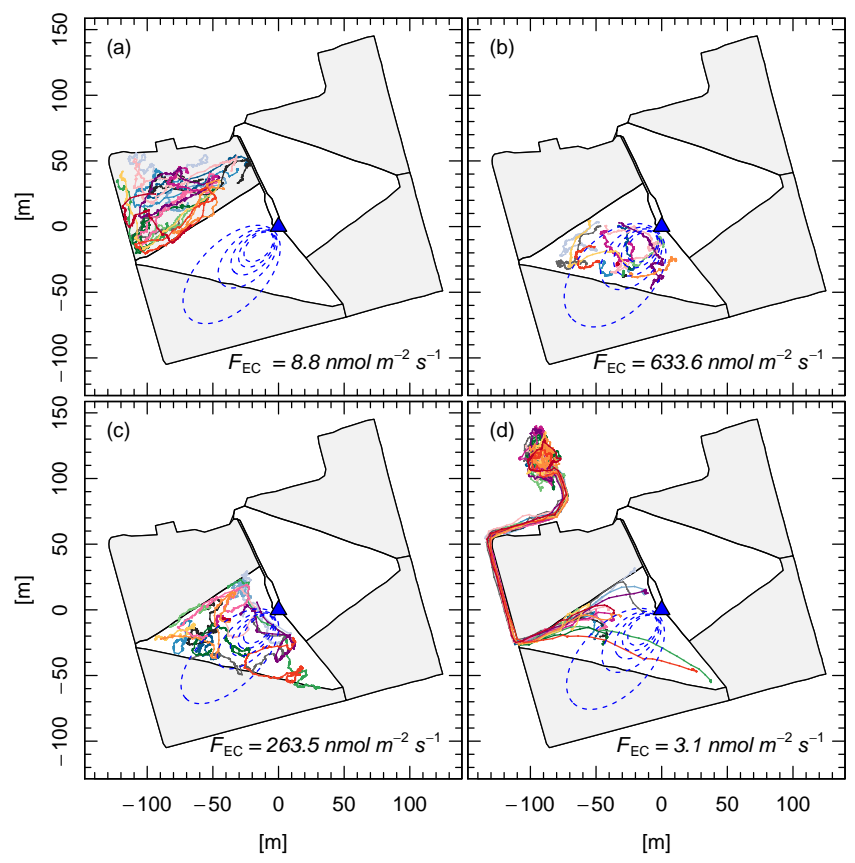

Figure 5. Four examples of $30 \mathrm{~min}$ intervals with similar wind and footprint conditions (blue isolines) but different cow distribution and observed fluxes $\left(F_{\mathrm{EC}}\right)$. For each cow, the registered GPS position ( $5 \mathrm{~s}$ resolution over $30 \mathrm{~min}$ ) is marked with a line of a different color. Paddocks representing near cows cases are white and far cows are gray. (a) No cows in the footprint, i.e. soil fluxes are measured, (b-d) the higher the number and residence time of cows in the footprint the larger the observed flux.

\subsection{FIELD method for deriving animal $\mathrm{CH}_{4}$ emission without position information}

EC measurements are frequently performed over pastures, but usually no detailed information on the position and exact number of animals and specific occupation times are available. If at least the average stocking rate over the grazing period is available and under the assumption that the cows are uniformly distributed over the entire pasture, the timeaveraged cow emissions can be calculated as

$$
\left\langle E_{\text {cow }}\right\rangle=\left(\left\langle F_{\mathrm{EC}}\right\rangle-\left\langle F_{\text {soil }}\right\rangle\right) \cdot A_{\text {field }} \cdot \frac{1}{\left\langle n_{\text {cow }}\right\rangle},
$$

with $\left\langle F_{\mathrm{EC}}\right\rangle$ denoting the mean observed $\mathrm{CH}_{4}$ flux of the grazing period, $A_{\text {field }}$ the total pasture area, and $\left\langle n_{\text {cow }}\right\rangle$ the mean number of cows on the study field over the grazing season. $\left\langle n_{\text {cow }}\right\rangle=6.6$ heads is calculated as the total number of cows of each 30 min interval with cows on the study field plus onehalf of the number of cows when the cows were moved between barn and pasture divided by the total number of $30 \mathrm{~min}$ intervals of the grazing period. For comparability reasons, the same $F_{\text {soil }}$ results (selected based on GPS data) were used for all three methods. It should be noted that an appropriate determination of the soil flux may be difficult without any cow position information.

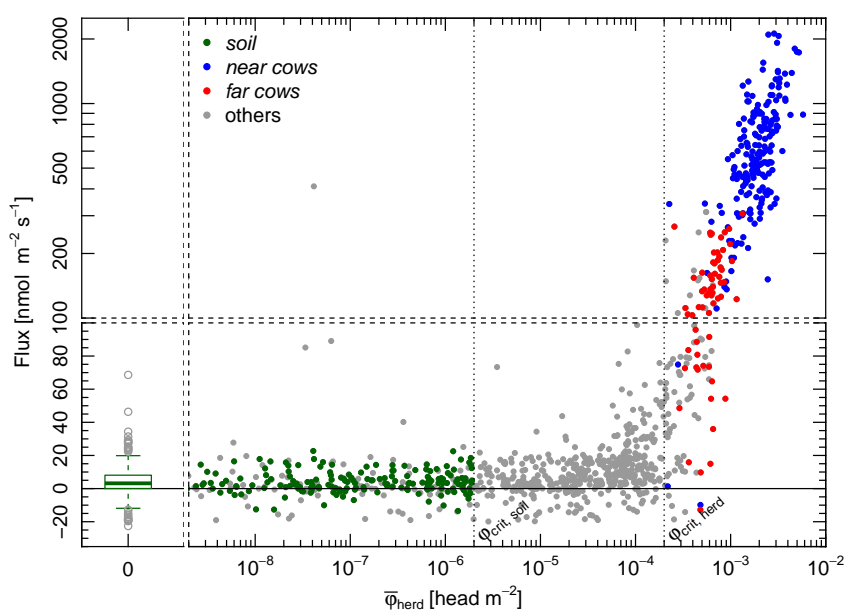

Figure 6. Observed $\mathrm{CH}_{4}$ fluxes plotted against the mean herd footprint weight $\left(\bar{\varphi}_{\text {herd }}\right)$. Cases selected for the calculation of the soil flux (green) and cow emissions (blue/red) are marked in dark colors. The remaining points (gray) represent discarded outliers and cases with intermediate $\bar{\varphi}_{\text {herd }}$ values (i.e., with low but not negligible cow influence).

\section{Results}

\subsection{Methane fluxes with and without cows}

Observed $30 \mathrm{~min} \mathrm{CH}_{4}$ fluxes varied between -150 and $2801 \mathrm{nmol} \mathrm{m}^{-2} \mathrm{~s}^{-1}$ during the grazing season. Cases with cows close to the sensor revealed strong fluxes (Fig. 5b and c). For cases with no cows in the FP (Fig. 5a) or with cows further away, measured fluxes were very small. For the cow emission calculations with FP consideration, fluxes were divided into cases with near cows (Fig. 5 white paddocks) and far cows (Fig. 5 gray paddocks).

For a systematic assessment of the relationship between $\mathrm{CH}_{4}$ flux and cow position and for the separation of cases representing pure soil fluxes, all quality selected fluxes were plotted against $\bar{\varphi}_{\text {herd }}$ in Fig. 6. It shows a clear relationship with a strong increase of fluxes only in the highest $\bar{\varphi}_{\text {herd }}$ range. Cases with near cows led to generally higher FP weights and fluxes than for the far cows cases. Based on Fig. 6, a threshold of $2 \times 10^{-4}$ head m ${ }^{-2}$ ( $\varphi_{\text {crit, herd }}$ ) was determined as the lower cut off for cow-affected fluxes to be used for the calculation of $E_{\text {cow }}$. Cases with $\bar{\varphi}_{\text {herd }}$ below $\varphi_{\text {crit, soil }}=2 \times 10^{-6}$ head $^{-2}$ were classified as soil fluxes. The exclusion of cases with $\bar{\varphi}_{\text {herd }}$ between the two critical limits ensured that fluxes with potential influence by the cows grazing on the neighboring pasture were removed.

The soil flux values were found to be generally small but mostly positive in sign (typically in the range 0 to $15 \mathrm{nmol} \mathrm{m}^{-2} \mathrm{~s}^{-1}$ Fig. 6), indicating continuous small emissions by the soil and surface processes. The accuracy of these fluxes was difficult to quantify because they mostly had no well-defined peak in the covariance function and thus $92 \%$ 


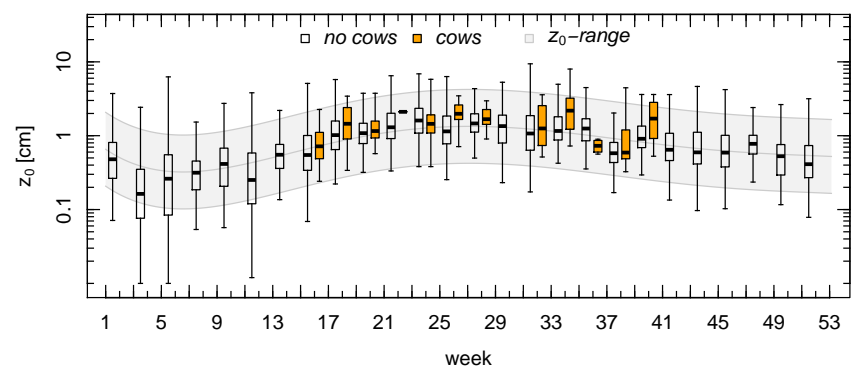

Figure 7. Fortnightly distributions (box plots) of calculated roughness length $\left(z_{0}\right)$ for wind speeds $>1.5 \mathrm{~m} \mathrm{~s}^{-1}$ separated for cases with no cows in the FP (white boxes) and cases with cows present in the FP (orange). Whiskers for the cow cases cover the full data range, outliers for no cows cases are not shown. The gray area indicates the $z_{0}$ range where the $30 \mathrm{~min} z_{0}$ value was accepted for FP evaluation. The middle curve in the gray range represents the sixth-order polynomial fit to the values without cows.

had to be calculated at the fixed lag. Even though temporal variations in median diurnal and seasonal cycles were observed (in the range of 1 to $7 \mathrm{nmol} \mathrm{m}^{-2} \mathrm{~s}^{-1}$ ), it was unclear whether these can be attributed to effects of environmental drivers or they result from non-ideal statistics and selection procedures. Also, varying small contributions from cows on neighboring upwind fields could not be excluded. Therefore we used a conservative overall average estimate for the soil flux of $4 \pm 3 \mathrm{nmol} \mathrm{m}^{-2} \mathrm{~s}^{-1}$ with the uncertainty range of $\pm 50 \%$ covering the temporal variation of medians indicated above.

\subsection{Footprints and cow influence}

\subsubsection{Roughness length}

The 30 min values of the roughness length $z_{0}$ determined for wind speeds $>1.5 \mathrm{~m} \mathrm{~s}^{-1}$ showed a systematic variation over the year peaking in summer (Fig. 7), when the vegetation height ranged between 5 and $15 \mathrm{~cm}$. Fortnightly medians for cases with no cows in the FP ranged from 0.16 to $1.6 \mathrm{~cm}$ and corresponded well to the parameterized $z_{0}$. Cows in the FP (withers height c. $150 \mathrm{~cm}$ ) slightly influenced $z_{0}$. The effect was distance dependent (Fig. 8). For cases with high FP weights of the cows (i.e., cows closer to the EC tower), $z_{0}$ was systematically up to $2 \mathrm{~cm}$ higher than the average parameterized $z_{0}$. However, there was still a considerable scatter of individual values and variation with time. The range limits for $z_{0}$ (gray range in Fig. 7) were necessary to filter implausible individual values under low wind or otherwise disturbed conditions. However, they were sufficiently large to include most of the cases influenced by cows. While for soil fluxes not influenced by cows $16 \%$ ( $5 \%$ below/11\% above) of the calculated $z_{0}$ values lay outside the accepted $z_{0}$ range, the respective portion was only slightly higher $(2 \%$ below $/ 18 \%$ above) for cases with cows in the FP.

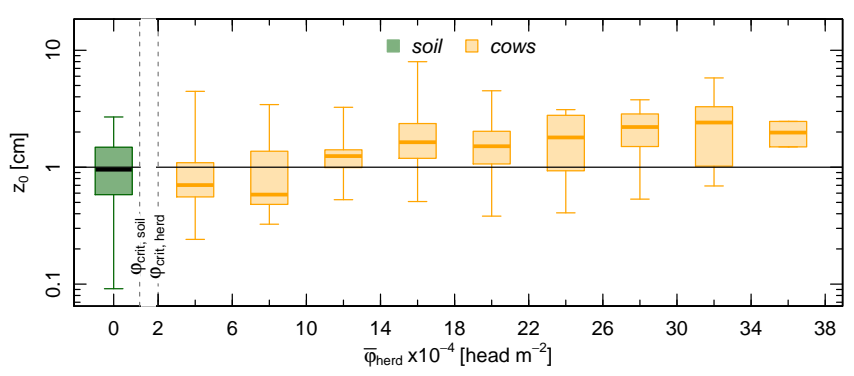

Figure 8. Effect of cows on roughness length $\left(z_{0}\right)$. Box plots of $30 \mathrm{~min} z_{0}$ values determined by Eq. (2) for $\bar{u}>1.5 \mathrm{~m} \mathrm{~s}^{-1}$ as a function of average footprint weight of the cow herd $\left(\bar{\varphi}_{\text {herd }}\right)$ based on GPS data. Whiskers cover the full data range. Orange for cases with cows, green for cases with no cows in the footprint.
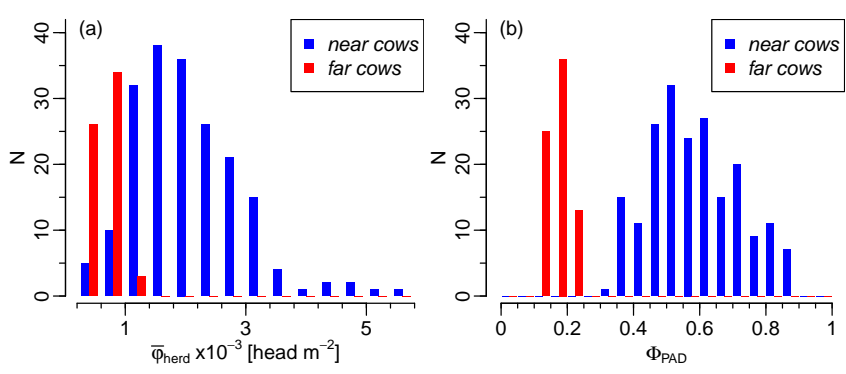

Figure 9. Histogram of footprint contributions (a) of cow positions used in the GPS method and (b) of occupied paddock area used in the PAD method. Cases are separated for distance of the cow herd from the EC tower in near cows and far cows.

\subsubsection{Footprint weights of cows and paddocks}

Average herd FP weights (Eq. 3) ranged up to $5.8 \times 10^{-3}$ and $1.4 \times 10^{-3}$ head m$^{-2}$ for the near cows and far cows cases (Fig. 9a). On the lower end they were limited by the cutoff value $\varphi_{\text {crit, herd. }}$ The distribution of the near cows cases showed a pronounced right tail whereas the far cows cases were more left skewed. Figure $9 \mathrm{~b}$ shows the FP fraction of the paddock in which the cows were present and which were used to calculate the emissions with the PAD method (Eq. 6). FP fractions for far cows were always lower than $25 \%$ of the total FP area. For the majority of the near cows cases the contribution to the measured flux was more than $40 \%$.

\subsection{Methane emissions per cow}

\subsubsection{Overall statistics}

The separation of fluxes into the classes near cows and far cows resulted in 194 and 63 thirty-minute GPS-based cow emission values, respectively. Using the PAD method, the corresponding numbers were only slightly higher (Table 1). Table 2 shows the estimated cow emissions for the three emission calculation schemes and for the two distance classes (near cows and far cows) if applicable. Emissions 
Table 2. Methane emissions calculated with known cow position (GPS) or occupied paddock area (PAD) for different distances of the cow herd to the EC tower (near, far), and calculated without using cow position information (FIELD). All values, except $\mathrm{n}$, are in units $\mathrm{g} \mathrm{CH}_{4}$ $\operatorname{head}^{-1} \mathrm{~d}^{-1}$.

\begin{tabular}{lrrrrr}
\hline & \multicolumn{2}{c}{ GPS } & \multicolumn{2}{c}{ PAD } & FIELD \\
\cline { 2 - 6 } & near cows & far cows & near cows & far cows & \\
\hline Mean & 423 & 282 & 443 & 319 & $389^{\mathrm{a}} / 470^{\mathrm{b}}$ \\
\pm 2 SE & \pm 24 & \pm 32 & \pm 32 & \pm 40 & $\pm 184^{\mathrm{b}}$ \\
Median & 408 & 296 & 405 & 323 & $348^{\mathrm{b}}$ \\
SD & 168 & 124 & 226 & 173 & $243^{\mathrm{b}}$ \\
$n$ & 194 & 63 & 198 & 74 & $7^{\mathrm{b}}$ \\
\hline
\end{tabular}

${ }^{a}$ Mean of all available 30 min data over the entire grazing period (in contrast to the second value).

b Statistical values calculated based on monthly results (April-October)

calculated for the near cows cases were significantly larger than emissions calculated for the far cows cases. The uncertainty of the mean (2 SE, calculated according to Gaussian error propagation) was lowest for the GPS method near cows. Emission results calculated with the PAD method were comparable to those of the GPS method considering the distance classes. The difference between median and mean values for GPS and PAD method were relatively small indicating symmetric distribution of individual values. Because the result of the FIELD method was calculated as temporal mean over the entire grazing period (with many small soil fluxes and few large cow influenced fluxes, see Fig. 6), the uncertainty could not be quantified from the variability of the individual 30 min data. Therefore we applied the FIELD method also to monthly periods and estimated the uncertainty $\left( \pm 184 \mathrm{~g} \mathrm{CH}_{4}\right.$ head $\left.^{-1} \mathrm{~d}^{-1}\right)$ from those results $(n=7)$. It is much larger than for the two other methods and there is also a considerable difference between the two different mean values.

\subsubsection{Diurnal variations}

Average diurnal cycle analysis for the near cows cases (Fig. 10a) showed persistent $\mathrm{CH}_{4}$ emissions by the cows over the entire course of the day. For $4 \mathrm{~h}$ of the day, less than five values per hour were found, mainly around the two milking periods or during nighttime. Mean emissions per hour ranged from 288 to $560 \mathrm{~g} \mathrm{CH}_{4}$ head $^{-1} \mathrm{~d}^{-1}$ with the highest values in the evening and lowest in the late morning (disregarding hours with $n<5$ ). Although the two grazing periods (evening/night: 17:00 to 03:00, and morning/noon: 08:00 to 14:00) between the milking phases were not equally long, comparable numbers of values were available $(n=91$ vs. 103). After the morning milking, the emissions decreased slightly for the first $3 \mathrm{~h}$ followed by a slight increase. An almost opposite pattern could be found after the second milking in the afternoon.

The temporal pattern of cow activity classes (Fig. 10b) mainly followed the daylight cycle with grazing activity dominating during daytime and ruminating during darkness.

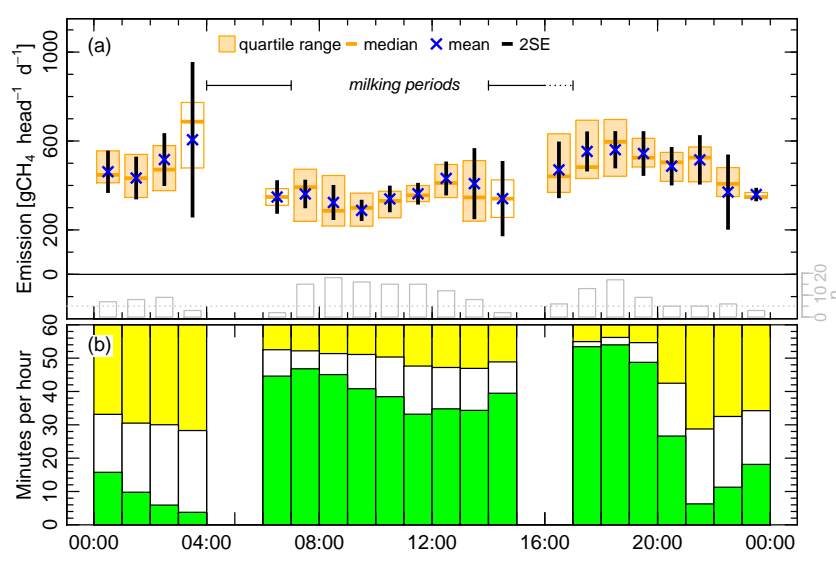

Figure 10. (a) Average diel variation of $\mathrm{CH}_{4}$ cow emissions (GPS method) for the near cows cases. White quartile range boxes indicate hours where less than five values are available. The uncertainty is given as 2 SE (black lines). White bars (bottom) show the number of values for each hour (right axis). The two gaps indicate the time when the cows were in the barn for milking. The dashed line in the second milking period indicates that the cows sometimes stayed longer in the barn. (b) Average time cows spent per hour for grazing (green), ruminating (yellow), and idling (white) activity, mean diel cycle for the entire grazing season.

Highest grazing time shares were observed right after the milking in the morning and in the later afternoon. While grazing and ruminating show clear opposing patterns, there is no distinct overall relationship with the $\mathrm{CH}_{4}$ emission cycle in Fig. 10a. However, maximum emissions in the evening hours coincide with maximum grazing activity.

\section{Discussion}

\subsection{Flux data availability and selection}

Fluxes used for cow emission calculations were less than $3 \%$ of the total number of $30 \mathrm{~min}$ intervals (Table 1 ). In av- 
erage years, 3.6 ha of pasture is approximately sufficient to feed 20 dairy cows by rotational grazing during the early season. The cold and wet spring in 2013 negatively influenced the productivity of the pasture. Therefore, additional pasture time, more than expected, outside the study field was needed to feed the animals. These neighboring pastures were used for $44 \%$ of the time but contributed typically less than $5 \%$ to the EC footprint, which was too low for a sufficient cow emission signal. Hence the data coverage for measuring cow emissions was lower than expected. The selection of acceptable wind directions and the limited probability that the wind came from the direction where the cows were actually present further reduced the number of cases selected as cow fluxes. Cow emissions with sufficient FP contribution mostly induced well-defined peaks in the cross-covariance function (Fig. 3) and were well above the flux detection limit (similar to that found by Detto et al., 2011). Even when the cows were present in the far paddocks, $94 \%$ of the fluxes already filtered by the other quality criteria were determined at dynamic lag times. This shows that further quality filtering with a stationarity test was not needed.

Individual soil exchange fluxes were mostly below the $3 \sigma$ detection limit of $20 \mathrm{nmol} \mathrm{m}^{-2} \mathrm{~s}^{-1}$ and more than $92 \%$ were determined at the fixed lag time. Detto et al. (2011) reported a detection limit of $\pm 3.78 \mathrm{nmol} \mathrm{m}^{-2} \mathrm{~s}^{-1}$ for a similar setup. The higher detection limit in this study has to be attributed to a different setup but also to the stronger polluted region with various agricultural $\mathrm{CH}_{4}$ sources (farm facilities). The uncertainty of the soil flux was of minor importance for the calculations of the cow emissions (Eqs. 4, 6 and 7) because the selected cow fluxes with significant FP contribution were about 2 orders of magnitude higher than $F_{\text {soil }}=4 \pm 3 \mathrm{nmol} \mathrm{m}^{-2} \mathrm{~s}^{-1}$ (Fig. 6). Soil fluxes observed here are of similar magnitude to fluxes measured in other studies: $\mathrm{CH}_{4}$ fluxes in the order of 0 to $10 \mathrm{nmol} \mathrm{m}^{-2} \mathrm{~s}^{-1}$ are reported from a drained and grazed peatland pasture (Baldocchi et al., 2012), fluxes around zero seldom larger than $25 \mathrm{nmol} \mathrm{m}^{-2} \mathrm{~s}^{-1}$ for a grassland in Switzerland after renovation (Merbold et al., 2014), and fluxes between -1.3 and $9.6 \mathrm{nmol} \mathrm{m}{ }^{-2} \mathrm{~s}^{-1}$ from a sheep grazed grassland measured by chambers (Dengel et al., 2011).

Methane fluxes from pasture always include fluxes from animal droppings (dung and urine). Therefore the soil fluxes referred to here are the combination of fluxes from the soil microbial community and fluxes from dung/urine which normally dominate the pure soil fluxes (Flessa et al., 1996). Emissions from cattle dung were estimated to be $0.778 \mathrm{~g}$ $\mathrm{CH}_{4}$ head $^{-1} \mathrm{~d}^{-1}$ (Flessa et al., 1996) and from Finnish dairy cows to $470 \mathrm{~g} \mathrm{CH}_{4} \mathrm{ha}^{-1}$ over a 110 day grazing period (Maljanen et al., 2012). The soil flux in the present study $\left(16 \mathrm{~g} \mathrm{ha}^{-1} \mathrm{~d}^{-1}\right)$ is around 3 times higher than the corresponding flux calculated with the literature numbers (Flessa et al. (1996): $5 \mathrm{~g} \mathrm{ha}^{-1} \mathrm{~d}^{-1}$ and Maljanen et al. (2013): $\left.4.3 \mathrm{~g} \mathrm{ha}^{-1} \mathrm{~d}^{-1}\right)$. Hence, the soil in the present study was a source of $\mathrm{CH}_{4}$. Factors which may explain differences in the present study and the literature are different animal breeds/types, soil and vegetation types, and soil and weather conditions. Additionally, the rotational grazing led to measurements of mixed fluxes from old and new dung patches.

\subsection{Source distance effect and footprint uncertainty}

In the GPS and PAD method, cow emissions were derived from the measured fluxes (corrected for soil exchange) with the help of the KM01 footprint model (Eqs. 4 and 6). Although it can be assumed that the cows emitted the same amount of $\mathrm{CH}_{4}$ whether they grazed in the far or near paddocks, a systematic effect of their distance from the EC tower was found (see near cows vs. far cows results in Table 2). The accuracy of the emissions depends on the accuracy of the flux measurement and on the accuracy of the FP model. The FP weight gets smaller and thus its relative accuracy decreases further away from the EC tower. This led to larger systematic uncertainties for calculations in the far cows cases compared to the near cows cases.

One potential error source in the FP calculation could be the choice of $z_{0}$. The observed course of $z_{0}$ over the year (Fig. 7) coincides with the herbage productivity during the season and corresponds to around $1 / 10$ of the grass height. The presence of the cows (in near cows paddocks) only slightly increased $z_{0}$ but the values remained in the expected range of $8 \mathrm{~mm}$ to $6 \mathrm{~cm}$ for short to long grass terrains (Wieringa, 1993). For occasional large obstacles (separated by at least 20 times the obstacle height) a value of $10 \mathrm{~cm}$ and larger is expected instead (WMO, 2008). Cows were moving obstacles in the FP, which obviously damped the enhancement of $z_{0}$. For the FP calculation, we therefore generally limited $z_{0}$ to a certain range around the mean seasonal course. For the majority of the cases, individually calculated $z_{0}$ values lay within this range, but in a minor fraction $(18 \%)$ of the cases with cows, they exceeded the range (see Fig. 7) and were truncated to the upper range limit. We tested the effect of a doubling of the parameterized $z_{0}$, as observed for the cow effect in Fig. 8, on $\Phi_{\mathrm{PAD}}$ for the near cows cases and found a moderate increase of around $17 \%$ which would lower the calculated cow emissions proportionally. Because the truncation effect was small and only applied to few cases, we consider the uncertainty in $z_{0}$ as not important for our cow emission results. In particular, it cannot explain the observed mean difference between near cows and far cows cases.

We chose the KM01 footprint model because the model uses an analytical solution and the calculation is fast compared to numerical particle models (e.g., backward Lagrangian stochastic models; bLS), which describe turbulence structure in a more complex way. Kljun et al. (2003) compared the KM01 model to a bLS model and found in general good agreements. However, the KM01 model underestimates the FP weight compared to the bLS model around the maximum of the FP function $\varphi_{\max }$ and overestimates the FP weight further downwind (see figures in Kljun et al., 2003). 
Integration over larger parts of the FP extension may balance this over-/underestimation. In the present study, the position of $\varphi_{\max }$ typically laid within $30 \mathrm{~m}$ of the EC tower (in PAD2 or PAD5). Thus for the near cows cases with animals typically within $60 \mathrm{~m}$ distance, such a balancing effect can be assumed. For the far cows cases, the KM01 model generally tends to overestimate the FP weights and thus the resulting emissions were underestimated on average. According to Kljun et al. (2003), the KM01 model also underestimates the FP weights in the direct vicinity of the EC tower (few meters). A detailed analysis of the cow positions (data not shown) revealed that in $68 \%$ of the near cows cases, animals were present in distances $<2 / 3 \varphi_{\max }$ from the tower. But in less than $5 \%$ of the cases, more than a tenth of the $30 \mathrm{~min}$ was affected. Hence the influence on the $\bar{\varphi}_{\text {herd }}$ was generally small.

The analytical model solution by KM01 was developed for ground-level sources. However, while the cow's mouth and nose (respiration source) are close to the surface during grazing, they may be elevated up to $\sim 1 \mathrm{~m}$ during other activities. Unfortunately, this effect could not be evaluated with the KM01 model. However, very recently McGinn et al. (2015) investigated the effect of elevated cow emissions for a micrometeorological flux method that also uses turbulent dispersion modeling. They found no significant difference in their results between simulations with sources at the surface and at $0.5 \mathrm{~m}$ height. It needs to be investigated in the future whether or not this finding is also valid for the EC flux footprint weight.

\subsection{Comparison to published respiration chamber results}

While measured methane EC fluxes depend on site and environmental conditions and are therefore not directly comparable to other studies, this is much more feasible for the average cow emissions derived by the GPS method and the two alternative methods (PAD and FIELD) described in Sect. 2.3-2.5. It can be assumed that dairy cows of similar breed and weight and with comparable productivity (milk yield) have a similar gross energy consumption and $\mathrm{CH}_{4}$ emission. We therefore collected literature results from Swiss respiration chamber studies selected for a mean milk yield in the range of 20 to $25 \mathrm{~kg} \mathrm{~d}^{-1}$ around the mean milk yield of the present study $\left(22.7 \mathrm{~kg} \mathrm{~d}^{-1}\right)$. Most of those studies aimed to find diets that reduce $\mathrm{CH}_{4}$ emissions based on different forage types and supplements. Cow diets therefore varied among all studies but always fulfilled animal nutrient requirements. One value from van Dorland et al. (2006) which showed very low $\mathrm{CH}_{4}$ emissions due to special diet supplements was excluded from Table 3. Mean body weight of cows in the present study $(640 \mathrm{~kg})$ was in the upper range of body weight in the selected chamber measurements.

The mean $\mathrm{CH}_{4}$ emission over all selected studies of $404 \mathrm{~g}$ $\mathrm{CH}_{4}$ head $^{-1} \mathrm{~d}^{-1}$ agrees very well with emissions measured
Table 3. Methane emissions from open-circuit respiration chamber measurements of Holstein and Swiss Brown breeds selected for milk yield and body weight comparable to cows in the present study. Hindrichsen et al. (2006a) used Swiss Brown breeds only.

\begin{tabular}{lrrr}
\hline Reference & $\begin{array}{r}\text { Emission } \\
\left(\mathrm{g} \mathrm{CH}_{4}\right. \\
\left.\text { head }^{-1} \mathrm{~d}^{-1}\right)\end{array}$ & $\begin{array}{r}\text { Body } \\
\text { weight } \\
(\mathrm{kg})\end{array}$ & $\begin{array}{r}\mathrm{ECM}^{1} \\
\left(\mathrm{~kg} \mathrm{~d}^{-1}\right)\end{array}$ \\
\hline van Dorland et al. (2006) & 428 & 669 & 23.5 \\
van Dorland et al. (2006) & 413 & 669 & 24.4 \\
van Dorland et al. (2007) & 424 & 641 & 24.5 \\
Hindrichsen et al. (2006a) & 415 & 586 & 20.0 \\
Hindrichsen et al. (2006a) & 379 & 583 & 20.0 \\
Hindrichsen et al. (2006a) & 374 & 594 & 21.0 \\
Hindrichsen et al. (2006b) & 414 & 619 & 22.8 \\
Münger and Kreuzer (2006) & 387 & 593 & 22.9 \\
\hline mean & 404 & 619 & 22.4 \\
SD & 21 & 36 & 1.8 \\
\hline
\end{tabular}

${ }^{1}$ ECM: energy-corrected milk yield.

2 Mean values of lactation week 8,15 , and 23 .

by EC for the near cows cases of $423 \mathrm{~g} \mathrm{CH}_{4}$ head $^{-1} \mathrm{~d}^{-1}$ (difference of only $5 \%$, within uncertainty range, see Table 2 ). The deviation for the PAD near cows results is about twice as large. The far cows results for GPS and PAD methods show even larger but negative deviations from the literature mean. The result of the FIELD method applied to the entire grazing period also shows a good agreement but we consider that as rather coincidental because the estimated uncertainty of monthly values as well as the deviation of their mean and median is much larger.

Based on the FP uncertainty considerations in Sect. 4.2 and the agreement with the recent literature values, we consider the GPS near cows results as the most reliable in this study. They were derived from only large fluxes with relatively low uncertainty. Therefore, the following discussion focusses on the GPS near cows results and uses them as reference for the comparison with the other results.

\subsection{Systematic and random-like variations of cow emission}

Our result show only a moderate diel cycle (Fig. 10a) with highest emissions in the evening and lowest before noon (hourly means $\pm 30 \%$ around overall mean). Although the timing of maximum emissions coincides with maximum grazing activity, the general diel variation cannot be explained satisfactorily by the observed cow activities (Fig. 10b). On the other hand, the emission pattern shows some correlation to the stability conditions, which were also subject to a distinct diel cycle (predominantly unstable conditions from daybreak until early evening and stable conditions during evening and night). Therefore the methodologyinduced effect of stability (e.g., via FP calculation) on the observed diel emission cycle cannot be fully excluded. 


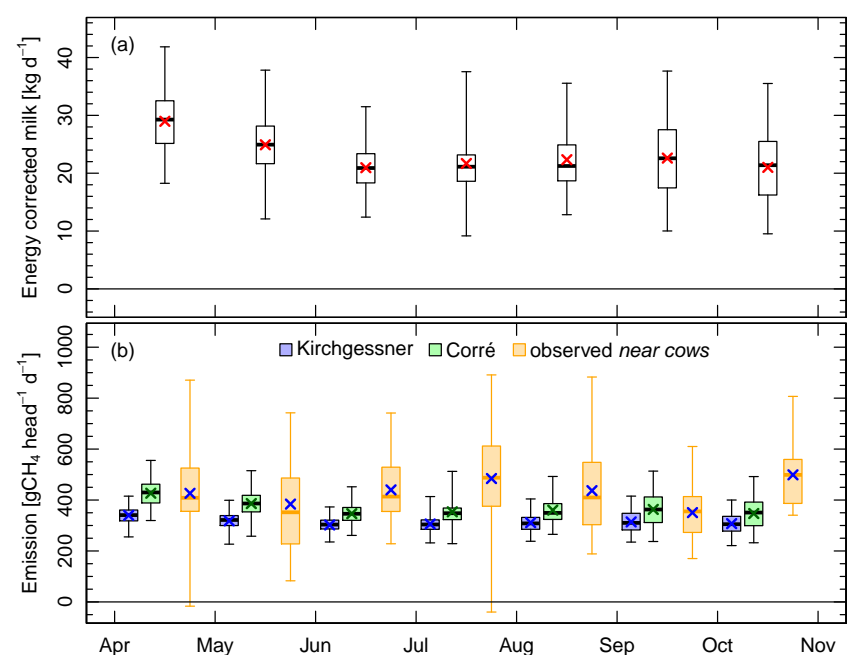

Figure 11. Monthly aggregated distribution of (a) energy-corrected daily milk yield (ECM) of the individual cows in the herd, and (b) cow methane emissions as observed in this study (near cows cases) and modeled as a function of ECM and cow body weight $(m)$ according to $10+4.9 \cdot \mathrm{ECM}+1.5 \cdot m^{0.75}$ (Kirchgessner et al., 1995) and $(50+0.01 \cdot \mathrm{ECM} \cdot 365) / 365 \cdot 100$ (Corré, 2002). Crosses indicate mean values, boxes represent interquartile ranges, and whiskers cover the full data range.

Increasing emission fluxes during daytime hours were also found over a sheep pasture by Dengel et al. (2011). But their nighttime fluxes were much smaller (close to zero) compared to daytime. Laubach et al. (2013) observed maximum $\mathrm{CH}_{4}$ emissions within $2 \mathrm{~h}$ after maximum feeding activity of cattle. Those cattle were fed before noon with imported fodder (all animals fed at the same time), whereas the cows in the present study themselves determined their grazing activity time throughout the day. Obviously, this is reflected in the less pronounced diel cycle.

To assess and interpret potential systematic effects of variations in cow performance (among animals in the herd and with time over the grazing season) we used published emission models based on observed productivity parameters (see Ellis et al., 2010). Figure 11 compares the results of two models (Corré, 2002; Kirchgessner et al., 1995) estimating cow emissions from recorded milk yield and body weight with results of this study. Although milk yield showed a general decrease over the first 3 months and a considerable variability within the herd, the effect on $\mathrm{CH}_{4}$ emissions according to the models was relatively small. The observed monthly emissions showed a larger variability which cannot be explained by the variability of cow performance.

Although the mean emissions observed in this study agree well with literature values the variation of the individual 30 min emissions is large (relative SD of $41 \%$ for GPS near cows, see Table 2). It is a combination of various effects with major contributions of the discussed diel variation, the stochastic uncertainty (short-term variability) of turbulence,

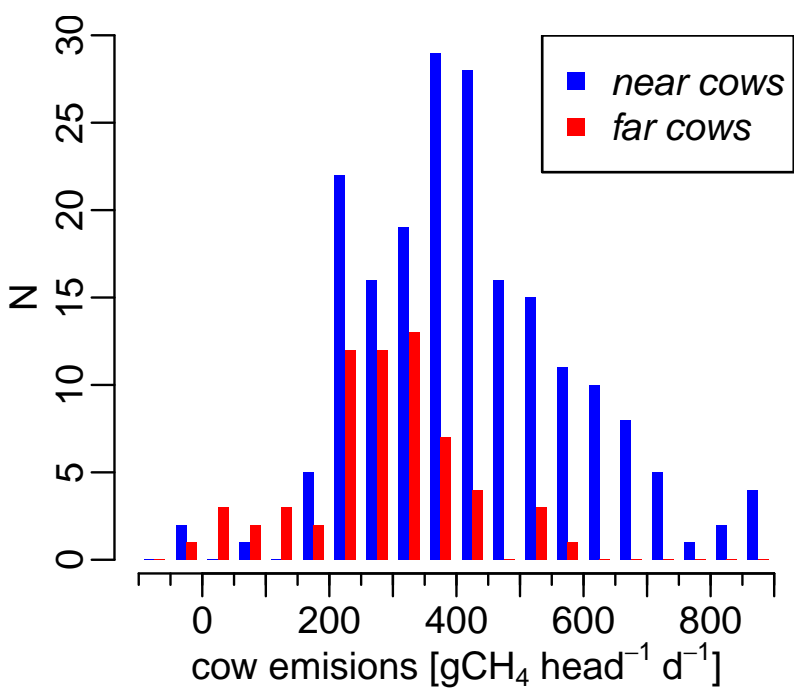

Figure 12. Histogram of cow emissions for near cows and far cows for the GPS method (according to Eqs. 3 and 4).

and the changing source distribution (various numbers of cows in the FP and moving). Very similar relative variability of 30 min fluxes was reported in a study using the micrometeorological bLS method (Laubach et al., 2014). Similar to Laubach et al., the large scatter of our individual emission values showed a fairly random-like (normal) distribution (Fig. 12) with only a minor deviation between mean and median. This distribution is clearly more symmetric than the corresponding distribution of cow FP weights (Fig. 9a). Based on this behavior, the estimated uncertainty range of the overall mean cow emissions calculated according to Gaussian error propagation rules is considered as representative.

\subsection{Relevance of cow position information}

In an intensive rotational grazing system, the cows are expected to effectively graze the entire paddock area. On shorter timescales of $30 \mathrm{~min}$ (Fig. 5) this assumption is often not fulfilled. For a grazing rotation phase of 2 days, the example in Fig. 13a shows that the cows indeed visited the entire paddock, but their position distribution was not uniform with higher densities in the central part of the paddock. Even over the entire grazing season, some inhomogeneity in the cow density distribution persisted (Fig. 13b). Despite this inhomogeneity, the mean emission calculated with the PAD method (implicitly assuming homogeneous cow distribution within the paddock) was comparable to the emission based on GPS data (Table 2), yet with a larger uncertainty range. Thus the hypothesis that more detailed information leads to better results was not clearly verified in this case. Apparently the limited size and the geometric arrangement of the paddocks in relation to typical extension of the FP area in the main wind sectors limited the value of the more detailed GPS information. 


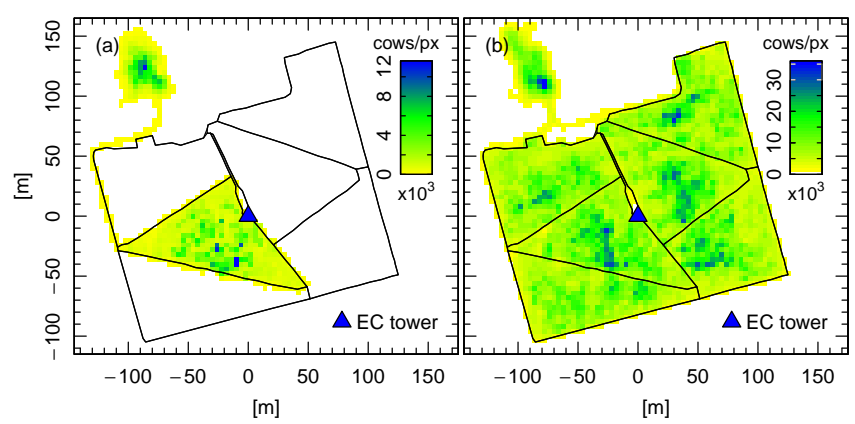

Figure 13. Cow density distribution (a) for one grazing cycle (i.e., two consecutive days) and (b) for the entire study field integrated over the full grazing season in 2013. The color of each pixel $(4 \times 4 \mathrm{~m})$ represents the number of data points collected at $5 \mathrm{~s}$ time resolution with the GPS trackers of all cows. Note the different color scales.

The PAD method uses a similar level of cow position information as other micrometeorological experiments applying the bLS approach (Laubach et al., 2008, 2013; Laubach and Kelliher, 2005; McGinn et al., 2011). The bLS models use the geometry of the paddock area and perform a concentration FP calculation (instead of the flux FP used here). The size of the paddock in those experiments ( 0.1 to $2 \mathrm{ha}$ ) was of the same order of magnitude as the paddock size in this study. Although the density of grazing animals in Laubach et al. (2013) was 5 times higher than the average density of 33 heads ha ${ }^{-1}$ in this study, they reported systematic effects of uneven cow distribution within the paddock on derived mean cow emissions, which was associated to the location where the fodder was available. They found a discrepancy of up to $+68 \%$ between their reference $\mathrm{SF}_{6}$ technique and the bLS model using concentration profile measurements at a single mast. The bLS experiments with line-averaging concentration measurements yielded generally better results because they are less sensitive to the source distribution. The corresponding uncertainties were similar to uncertainties found in this study.

Although some inhomogeneity of the animal density was found within the paddocks, the rotational grazing system prevented major differences among them in the long term (Fig. 13b). This may not be the case for a free range grazing system without subdivision of the field into paddocks, like e.g., in the study by Dengel et al. (2011). In such a case, a larger-scale inhomogeneity may develop leading to a systematic under- or overrepresentation of the animals in the flux FP (in the main wind sectors), and the FIELD method without cow position information would yield biased results. As an alternative to the use of GPS sensors on individual animals, their position could be monitored by the use of digital cameras and animal detection software (Baldocchi et al., 2012).

The problem discussed so far for $\mathrm{CH}_{4}$ also exists for the investigation of $\mathrm{CO}_{2}$ flux measurements at pasture sites because of the considerable contribution of animal respiration to the net ecosystem exchange. If joint $\mathrm{CO}_{2}$ and $\mathrm{CH}_{4}$ fluxes are available at the site, $\mathrm{CH}_{4}$ can be used as a tracer for ruminant-induced $\mathrm{CO}_{2}$ fluxes by using typical $\mathrm{CH}_{4} / \mathrm{CO}_{2}$ ratios of exhaled air found in respiration chamber measurements.

\section{Conclusions}

EC flux and GPS data were combined using an analytical FP model to derive animal-related $\mathrm{CH}_{4}$ emissions. A systematic effect of the distance from the EC tower to the source (cows) was found, which has to be attributed to the applied analytical FP model. It overestimates the FP weight of sources at large distances ( $>25$ times the measurement height). The problem may be avoided by using a more sophisticated Lagrangian dispersion model. The roughness length $z_{0}$ used as input for the FP model was moderately but systematically increased by the cows which should be taken into account.

The position information allowed for a reliable distinction of fluxes representing soil exchange without direct influence of cows. Although these fluxes were very low with a marginal effect on the determination of cow emissions (using cow position information), they are potentially more important for the annual $\mathrm{CH}_{4}$ and full GHG budget of the pasture. In our rotational grazing setup, the simple information on paddock occupation times led to comparable estimates of mean cow emissions like the more detailed GPS information. For other pasture flux sites with a different grazing system, cow position information may be more crucial to determine representative animal emissions and soil exchange fluxes. We conclude that EC measurements over pasture are sufficiently accurate to estimate mean $\mathrm{CH}_{4}$ emissions of animals on the pasture. Although the uncertainty makes it difficult to detect small differences in animal $\mathrm{CH}_{4}$ emissions during short-term experiments, the EC method is well suitable for assessing longer-term ecosystem GHG budgets that are necessary to improve national inventories.

Acknowledgements. We gratefully acknowledge the funding from the Swiss National Science Foundation (grant no. 205321_138300). We wish to thank Hubert Bollhalder, Roman Gubler, Veronika Wolff, Andreas Rohner, Manuel Schuler, Markus Jocher, Manuela Falk, Lukas Eggerschwiler, and Bernard Papaux for support with the sensors and in the field. We thank Daniel Bretscher for the collection of studies containing data of respiration chamber measurements and the discussion of these data, Robin Giger for graphical help with the figures, and Jörg Sintermann for provision of R code.

Edited by: E. Pendall 


\section{References}

Ammann, C., Brunner, A., Spirig, C., and Neftel, A.: Technical note: Water vapour concentration and flux measurements with PTR-MS, J. Environ. Qual., 6, 4643-4651, 2006.

Arrigo, Y., Chaubert, C., Daccord, R., Gagnaux, D., Gerber, H., Guidon, D., Jans, F., Kessler, J., Lehmann, E., Morel, I., Münger, A., Rouel, M., and Wyss, U.: Fütterungsempfehlungen und Nährwerttabellen für Wiederkäuer: das grüne Buch, 4th Edn., Eidgenössische Forschungsanstalt für Nutztiere, Zollikofen, Switzerland, 1999.

Aubinet, M., Grelle, A., Ibrom, A., Rannik, Ü., Moncrieff, J., Foken, T., Kowalski, A. S., Martin, P. H., Berbigier, P., Bernhofer, C., Clement, R., Elbers, J., Granier, A., Gruenwald, T., Morgenstern, K., Pilegaard, K., Rebmann, C., Snijders, W., Valentini, R., and Vesala, T.: Estimates of the annual net carbon and water exchange of forests: the EUROFLUX methodology, Adv. Ecol. Res., 30, 113-175, 2000.

Aubinet, M., Feigenwinter, C., Heinesch, B., Laffineur, Q., Papale, D., Reichstein, M., Rinne, J., and Van Gorsel, E.: Nighttime Flux Correction, in Eddy Covariance: A Practical Guide to Measurement and Data Analysis, edited by: Aubinet, M., Vesala, T., and Papale, D., Springer Netherlands, 133-157, 2012.

Baer, D. S., Paul, J. B., Gupta, M., and O'Keefe, A.: Sensitive absorption measurements in the near-infrared region using offaxis integrated-cavity-output spectroscopy, Appl. Phys. B Lasers Opt., 75, 261-265, 2002.

Baldocchi, D. D.: Assessing the eddy covariance technique for evaluating carbon dioxide exchange rates of ecosystems: past, present and future, Glob. Change Biol., 9, 479-492, 2003.

Baldocchi, D. D., Detto, M., Sonnentag, O., Verfaillie, J., Teh, Y. A., Silver, W., and Kelly, N. M.: The challenges of measuring methane fluxes and concentrations over a peatland pasture, Agric. For. Meteorol., 153, 177-187, 2012.

Corré, W. J.: Agricultural land use and emissions of methane and nitrous oxide in Europe, Report 40, Plant Research International, Wageningen, 2002.

Dabberdt, W. F., Lenschow, D. H., Horst, T. W., Zimmermann, P. R., Oncley, S. P., and Delany, A. C.: Atmosphere-surface exchange measurements, Science, 260, 1472-1481, 1993.

Dengel, S., Levy, P. E., Grace, J., Jones, S. K., and Skiba, U. M.: Methane emissions from sheep pasture, measured with an openpath eddy covariance system, Glob. Change Biol., 17, 35243533, 2011.

Detto, M., Verfaillie, J., Anderson, F., Xu, L. and Baldocchi, D.: Comparing laser-based open- and closed-path gas analyzers to measure methane fluxes using the eddy covariance method, Agric. For. Meteorol., 151, 1312-1324, 2011.

Ellis, J. L., Bannink, A., France, J., Kebreab, E., and Dijkstra, J.: Evaluation of enteric methane prediction equations for dairy cows used in whole farm models: Methane prediction in vivo farm models, Glob. Change Biol., 16, 3246-3256, 2010.

Flessa, H., Dörsch, P., Beese, F., König, H., and Bouwman, A. F.: Influence of Cattle Wastes on Nitrous Oxide and Methane Fluxes in Pasture Land, J Env. Qual., 25, 1366-1370, 1996.

Foken, T., Leuning, R., Oncley, S. R., Mauder, M., and Aubinet, M.: Corrections and Data Quality Control, in Eddy Covariance, edited by: Aubinet, M., Vesala, T., and Papale, D., Springer Netherlands, Dordrecht, 85-131, 2012a.
Foken, T., Aubinet, M., and Leuning, R.: The Eddy Covariance Method, in Eddy Covariance: A Practical Guide to Measurement and Data Analysis, edited by: Aubinet, M., Vesala, T., and Papale, D., Springer Netherlands, Dordrecht, 1-19, 2012b.

Graf, A., van de Boer, A., Moene, A., and Vereecken, H.: Intercomparison of Methods for the Simultaneous Estimation of ZeroPlane Displacement and Aerodynamic Roughness Length from Single-Level Eddy-Covariance Data, Bound.-Layer Meteorol., 151, 373-387, 2014.

Harper, L. A., Denmead, O. T., Freney, J. R., and Byers, F. M.: Direct measurements of methane emissions from grazing and feedlot cattle, J. Anim. Sci., 77, 1392-1401, 1999.

Hiller, R. V., Bretscher, D., DelSontro, T., Diem, T., Eugster, W., Henneberger, R., Hobi, S., Hodson, E., Imer, D., Kreuzer, M., Künzle, T., Merbold, L., Niklaus, P. A., Rihm, B., Schellenberger, A., Schroth, M. H., Schubert, C. J., Siegrist, H., Stieger, J., Buchmann, N., and Brunner, D.: Anthropogenic and natural methane fluxes in Switzerland synthesized within a spatially explicit inventory, Biogeosciences, 11, 1941-1959, doi:10.5194/bg-11-1941-2014, 2014.

Hindrichsen, I. K., Wettstein, H.-R., Machmüller, A., Knudsen, K. E. B., Madsen, J., and Kreuzer, M.: Digestive and metabolic utilisation of dairy cows supplemented with concentrates characterised by different carbohydrates, Anim. Feed Sci. Technol., 126, 43-61, 2006a.

Hindrichsen, I. K., Wettstein, H.-R., Machmüller, A., and Kreuzer, M.: Methane emission, nutrient degradation and nitrogen turnover in dairy cows and their slurry at different milk production scenarios with and without concentrate supplementation, Agric. Ecosyst. Environ., 113, 150-161, 2006b.

Kaimal, J. C. and Finnigan, J. J.: Atmospheric Boundary Layer Flows?: Their Structure and Measurement, Oxford University Press, New York, US, 1994.

Kirchgessner, M., Windisch, W., and Müller, H. L.: Nutritional factors affecting methane production by ruminants, in Ruminant physiology: Digestion, Metabolism, Growth and Reproduction, edited by: Engelhardt, W. V., Leonhard-Mare, S., Breve, G., and Giesecke, D., Ferdinand Enke Verlag, Stuttgart, 333-343, 1995.

Kljun, N., Kormann, R., Rotach, M. W., and Meixer, F. X.: Comparison of the Langrangian Footprint, Bound.-Layer Meteorol. 106, 349-355, 2003.

Kormann, R. and Meixner, F. X.: An analytical footprint model for non-neutral stratification, Bound.-Layer Meteorol., 99, 207-224, 2001.

Lassey, K. R.: Livestock methane emission: From the individual grazing animal through national inventories to the global methane cycle, Agric. For. Meteorol., 142, 120-132, 2007.

Laubach, J. and Kelliher, F. M.: Methane emissions from dairy cows: Comparing open-path laser measurements to profile-based techniques, Agric. For. Meteorol., 135, 340-345, 2005.

Laubach, J., Kelliher, F. M., Knight, T. W., Clark, H., Molano, G., and Cavanagh, A.: Methane emissions from beef cattle - a comparison of paddock- and animal-scale measurements, Aust. J Exp. Agric., 48, 132-137, doi:10.1071/EA07256, 2008.

Laubach, J., Bai, M., Pinares-Patiño, C. S., Phillips, F. A., Naylor, T. A., Molano, G., Cárdenas Rocha, E. A., and Griffith, D. W. T.: Accuracy of micrometeorological techniques for detecting a change in methane emissions from a herd of cattle, Agric. For. Meteorol., 176, 50-63, 2013. 
Laubach, J., Grover, S. P. P., Pinares-Patiño, C. S., and Molano, G.: A micrometeorological technique for detecting small differences in methane emissions from two groups of cattle, Atmos. Environ., 98, 599-606, 2014.

Leuning, R., Baker, S. K., Jamie, I. M., Hsu, C. H., Klein, L., Denmead, O. T., and Griffith, D. W. T.: Methane emission from freeranging sheep: a comparison of two measurement methods, Atmos. Environ., 33, 1357-1365, 1999.

Maljanen, M. E., Virkajärvi, P., and Martikainen, P.: Dairy cow excreta patches change the boreal grass swards from sink to source of methane, Agric. Food Sci., 21, 91-99, 2012.

McGinn, S. M., Turner, D., Tomkins, N., Charmley, E., BishopHurley, G., and Chen, D.: Methane Emissions from Grazing Cattle Using Point-Source Dispersion, J. Environ. Qual., 40, 22-27, doi:10.2134/jeq2010.0239, 2011.

McGinn, S. M., Flesch, T. K., Coates, T. W., Charmley, E., Chen, D., Bai, M., and Bishop-Hurley, G.: Evaluating Dispersion Modeling Options to Estimate Methane Emissions from Grazing Beef Cattle, J. Environ. Qual., 44, 97-102, doi:10.2134/jeq2014.06.0275, 2015

Merbold, L., Eugster, W., Stieger, J., Zahniser, M., Nelson, D., and Buchmann, N.: Greenhouse gas budget $\left(\mathrm{CO}_{2}, \mathrm{CH}_{4}\right.$ and $\left.\mathrm{N}_{2} \mathrm{O}\right)$ of intensively managed grassland following restoration, Glob. Change Biol., 20, 1913-1928, 2014.

Moore, C. J.: Frequency response corrections for eddy correlation systems, Bound.-Layer Meteorol., 37, 17-35, 1986.

Münger, A. and Kreuzer, M.: Methane emission as determined in contrasting dairy cattle breeds over the reproduction cycle, Int. Congr. Ser., 1293, 119-122, 2006.

Münger, A. and Kreuzer, M.: Absence of persistent methane emission differences in three breeds of dairy cows, Aust. J. Exp. Agric., 48, 77-82, doi:10.1071/EA07219, 2008.

Munger, J. W., Loescher, H. W., and Luo, H.: Measurement, Tower, and Site Design Considerations, in Eddy Covariance: A Practical Guide to Measurement and Data Analysis, edited by: Aubinet, M., Vesala, T., and Papale, D., Springer Netherlands, Dordrecht, 21-58, 2012.

Myhre, G., Shindell, D., Béron, F.-M., Collins, W., Fuglestvedt, J., Huang, J., Koch, D., Lamarque, J.-F., Lee, D., Mendoza, B., Nakajima, T., Robock, A., Stephens, G., Takemura, T., and Zhang, H.: Anthropogenic and Natural Radiative Forcing, in Climate Change 2013: The Physical Science Basis. Contribution of Working Group I to the Fifth Assessment Report of the Intergovernmental Panel on Climate Change, edited by: Stocker, T. F., Qin, D., Plattner, G.-K., Tignor, M., Allen, S. K., Boschung, J., Nauels, A., Xia, Y., Bex, V., and Midgle, P. M., Cambridge University Press, Cambridge, United Kingdom and New York, NY, USA, 659-740, 2013.

Neftel, A., Spirig, C., and Ammann, C.: Application and test of a simple tool for operational footprint evaluations, Environ. Pollut., 152, 644-652, 2008.

Peltola, O., Mammarella, I., Haapanala, S., Burba, G., and Vesala, T.: Field intercomparison of four methane gas analyzers suitable for eddy covariance flux measurements, Biogeosciences, 10, 3749-3765, 2013,

http://www.biogeosciences.net/10/3749/2013/

Pinares-Patiño, C. S., D'Hour, P., Jouany, J.-P., and Martin, C.: Effects of stocking rate on methane and carbon dioxide emissions from grazing cattle, Agric. Ecosyst. Environ., 121, 30-46, 2007.
R Core Team: R: A language and environment for statistical computing, R Foundation for Statistical Computing, Vienna, Austria, available from: http://www.R-project.org/, 2014.

Schmid, H. P., Grimmond, C. S. B., Cropley, F., Offerle, B., and $\mathrm{Su}, \mathrm{H}$.-B.: Measurements of $\mathrm{CO} 2$ and energy fluxes over a mixed hardwood forest in the mid-western United States, Agric. For. Meteorol., 103, 357-374, 2000.

Smith, P., Martino, D., Cai, Z., Gwary, D., Janzen, H., Kumar, P., McCarl, B., Ogle, S., O’Mara, F., Rice, C., Scholes, B., and Sirotenko, O.: Agriculture, in Climate Change 2007: Mitigation, Contribution of Working Group III to the Fourth Assessment Report of the Intergovernmental Panel on Climate Change, edited by: Metz, B., Davidson, O. R., Bosch, P. R., Dave, R., and Meyer, L. A., Cambridge University Press, Cambridge, United Kingdom and New York, NY, USA, 497-540, 2007.

Spirig, C., Neftel, A., Ammann, C., Dommen, J., Grabmer, W., Thielmann, A., Schaub, A., Beauchamp, J., Wisthaler, A., and Hansel, A.: Eddy covariance flux measurements of biogenic VOCs during ECHO 2003 using proton transfer reaction mass spectrometry, Atmos. Chem. Phys., 5, 465-481, doi:10.5194/acp-5-465-2005, 2005.

Tuzson, B., Hiller, R. V., Zeyer, K., Eugster, W., Neftel, A., Ammann, C., and Emmenegger, L.: Field intercomparison of two optical analyzers for $\mathrm{CH}_{4}$ eddy covariance flux measurements, Atmos. Meas. Tech., 3, 1519-1531, doi:10.5194/amt-3-1519-2010, 2010.

van Dorland, H. A., Wettstein, H.-R., Leuenberger, H., and Kreuzer, M.: Comparison of fresh and ensiled white and red clover added to ryegrass on energy and protein utilization of lactating cows, Anim. Sci., 82, 691-700, doi:10.1079/ASC200685, 2006.

van Dorland, H. A., Wettstein, H.-R., Leuenberger, H., and Kreuzer, M.: Effect of supplementation of fresh and ensiled clovers to ryegrass on nitrogen loss and methane emission of dairy cows, Livest. Sci., 111, 57-69, 2007.

Webb, E. K., Pearman, G. I. and Leuning, R.: Correction of flux measurements for density effects due to heat and water vapour transfer, Q. J. R. Meteorol. Soc., 106, 85-100, 1980.

Wieringa, J.: Representative roughness parameters for homogeneous terrain, Bound.-Layer Meteorol., 63, 323-363, 1993.

Witte, T. H. and Wilson, A. M.: Accuracy of WAAS-enabled GPS for the determination of position and speed over ground, J. Biomech., 38, 1717-1722, 2005.

WMO: Guide to meteorological instruments and methods of observation, World Meteorological Organization, Geneva, Switzerland, 2008.

Zehner, N., Niederhauser, J. J., Nydegger, F., Grothmann, A., Keller, M., Hoch, M., Haeussermann, A., and Schick, M.: Validation of a new health monitoring system (RumiWatch) for combined automatic measurement of rumination, feed intake, water intake and locomotion in dairy cows., Infomation Technol. Autom. Precis. Farming Int. Conf. Agric. Eng.-CIGR-AgEng 2012 Agric. Eng. Heal. Life Valencia Spain 08-12 July 2012, C-0438, 2012. 